\title{
Ponceau 2R Doped Poly (ST/MMA) as Fluorescent Solar Collectors and Evaluation Effect of Matrix on Their Field Performance
}

\author{
S. M. Reda ${ }^{1,2 *}$, Asla A. Al-Zahrani ${ }^{2}$ \\ ${ }^{1}$ Chemistry Department, Faculty of Science, Benha University, Benha, Egypt \\ ${ }^{2}$ Chemistry Department, College of Science for Girls, Dammam University, \\ Dammam, KSA \\ Email: safenazr@yahoo.com
}

Received October 8, 2012; revised November 16, 2012; accepted December 6, 2012

\begin{abstract}
Luminescent solar concentrators (LSCs) with styrene (ST) and methylmethacrylate (MMA) of different percentage as the matrix were prepared by a casting method using ponceau 2R. DSC has been used to compare the thermal stability of the different LSCs. FTIR spectroscopy shows that appearance of $-\mathrm{N}=\mathrm{N}$ - for ponceau $2 \mathrm{R}$ in all ST/MMA matrixes indicating that the highest stability of this kind of dye in these matrixes. The values of the optical band gap $\left(E_{g}\right)$ have been obtained from direct allowed transition before and after the samples have been exposed to sunlight for 9 weeks. Photodegradation studies revealed that the more photo-stable dye doped in PMMA matrix than in other matrixes. The results showed that the homo PMMA/ponceau 2R system has the highest fluorescence quantum yield $\left(Q_{f}\right)$. Therefore this sample can be selected for field performance of fluorescent solar collectors. The photovoltaic cell coupled with homo PMMA/2R LSC shows a maximum efficiency, 2\% compared to the normal one.
\end{abstract}

Keywords: Luminescent Solar Collectors; Ponceau 2R; Polymethylmethacrylate; Polystyrene; Photodegradation; Fluorescence Quantum Yield

\section{Introduction}

The luminescent solar collector (LSC) appears to be promising for low cost solar energy conversion into electrical energy. The luminescent solar concentrator (LSC) is a light-transparent plate like glasses or polymers with high refractive indices incorporating with a luminescent dopant which has a broad absorption band in the visible light region. Operation of the LSC is based on the absorption of solar radiation in a collector containing a fluorescent species in which the emission bands have little or no overlap with the absorption bands [1]. The emission light is trapped by total internal reflection and concentrate at the edges of the collector where a photovoltaic cell facing the edge of plate converts it into electricity. Because, polymethylmethacrylate (PMMA) and polystyrene (PS) bear all properties required for good LSC base material (highly transparent and high refractive index) and it is easy to prepare as sheets of desired shape and size. Therefore, doping of it with organic dyes may be a most useful combination for use in luminescence

"Present address: Chemistry Department, College of Science for Girls, Dammam University, Dammam, KSA. solar concentrators. Many experimental reports have detailed consideration of the preparation of LSCs doped with different luminescent dyes and the principles of LSCs dye photodegradation and optical efficiency has been discussed [1].

The performance of a LSC is determined by the spectroscopic properties of the dye doped in its matrix. Ponceau $2 \mathrm{R}$ is the one type of azo dyes which are important colorants and it is characterized by the presence of one azo group $(-\mathrm{N}=\mathrm{N}-)$ and constitute the largest class of dyes having extensive application in textiles, papers, leathers, gasoline, additives, foodstuffs and cosmetics $[2,3]$. Moreover, the ponceau $2 \mathrm{R}$ has optical properties help in improving the efficiency of LSC such as the high extinction coefficient, strong fluorescent properties and high photo stability.

The purpose of this paper is to copolymerize styrene and methylmethacrylate to obtain a product with properties between those of the individual homopolymers. The effect of type of substrate on photostability and fluorescence properties of ponceau $2 \mathrm{R}$ has been measured before and after exposure to sun light to attain the best conditions under which these LSCs will have high photosta- 
bility and enhance the solar cell conversion efficiency.

\section{Experimental}

\subsection{Preparation of LSCs}

The polymerization of MMA (Aldrich), ST (Aldrich) and MMA/ST was performed using benzoyl peroxide as initiator $(1 \mathrm{wt} \%)$ at $443 \mathrm{~K}$ for 7 hours $[4,5]$. The ST/MMA percentage in copolymer is $100 / 0,70 / 30,50 / 50,30 / 70$, and $0 / 100$ volume $\%$. The formed polymer left for several hours at room temperature to evaporate the solvent off. Plate samples of thickness $(\sqcup 0.02 \mathrm{~cm})$ and ponceau $2 \mathrm{R}$ (Aldrich) concentration of $0.374 \mathrm{mM} / \mathrm{L}$ were prepared by casting method where the dye was homogeneously diffused in the precast polymers. The chemical structure of the investigated dye is shown in Figure 1.

Shimadzu (1000-V9,4 Build 287 DSCQ) differential scanning calorimeter was used to determine the glass transition temperature of LSCs. Samples were scanned under nitrogen at a ramp rate of $10^{\circ} \mathrm{C} / \mathrm{min}$ and temperature ranging from room temperature to $773 \mathrm{~K}$. FTIR spectra were measured on Infrared Spectrophotometer (FTIR-Nicolet 6700) Thermo Scientific German in wave number range $\left(400-4000 \mathrm{~cm}^{-1}\right)$.

The outdoor testing for LSCs was carried out for 9 weeks, from March to May (summer of 2011) in Dammam, Eastern region of KSA in a range of solar intensity $\left(80-1200 \mathrm{~W} / \mathrm{m}^{2}\right)$. The intensity of solar light was measured by solar parameter (ISO-TECH.ISM410). The absorption spectra were recorder using UV Spectrophotometer (UV-1800 SHIMADZU) in the wavelength range $(200-900 \mathrm{~nm})$ at room temperature. The fluorescence spectra have been recorded using Perkin Elmer LS 55 Fluorescence Spectrofluorometer at excitation wavelength $500 \mathrm{~nm}$. The absorbance and emission spectra were recorded for the samples in the form of rectangular discs of area $\left(3 \times 1 \mathrm{~cm}^{2}\right)$ and thickness of $0.02 \mathrm{~cm}$.

\subsection{Photovoltaic Cell Coupled with PMMA/2R LSC}

A commercial solar cell of $\left(2 \times 1 \times 0.5 \mathrm{~cm}^{2}\right)$ was used in this work. Silicon oil was used as optical matching between LSC and the solar cell. The LSC with dimensions of $2 \times 1 \times 0.02 \mathrm{~cm}^{3}$ was used. The LSC was tested under

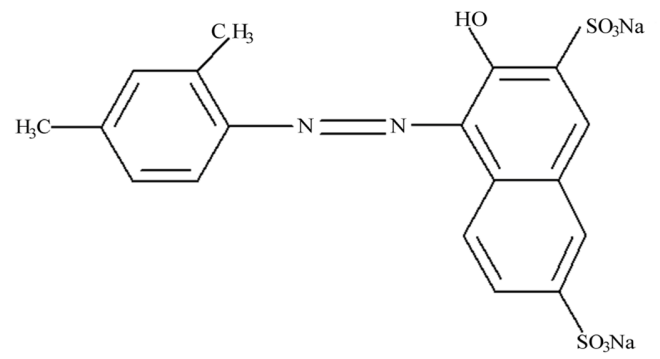

Figure 1. The molecular structure of ponceau $2 R$. direct sunlight illumination on April (2012). The efficiency of cell was measured before and after coupling with PMMA/ponceau 2R LSC.

The open-circuit voltage $\left(V_{o c}\right)$ and the short-circuit photocurrent $\left(I_{s c}\right)$ were measured at direct sunlight illumination intensity of $850 \mathrm{~W} / \mathrm{m}^{2}$ using Digital Voltmeter Sanwa Model CD 800 and Digital Electrometer Sanwa Model CD 800, respectively.

\section{Result and Discussion}

\subsection{Characterization of LSCs}

\subsubsection{Thermal Analysis (DSC)}

DSC was used to determine the glass transition temperature of LSCs. Figure 2 illustrates the DSC plots of LSCs of different ST/MMA percentage. The figure shows that the glass transition temperature $T_{g}$ have been decreased with increasing percentage of ST. This indicates that the thermal stability of LSC decrease by increasing styrene content [6]. The LSC of homo PMMA has the highest $T_{g}$ $\left(122^{\circ} \mathrm{C}\right)$ compared with the others matrixes. The higher thermal stability of PMMA/ponceau 2R system refers to the possibility of using it to prepare some solar collectors.

\subsubsection{FT-IR}

Figure 3 shows the IR spectra of LSCs of different ST/MMA percentage. As shown in this Figure the disappearance of aliphatic $\mathrm{C}=\mathrm{C}$ bands $\left(1680-1600 \mathrm{~cm}^{-1}\right)$ characterizing MMA from all PMMA matrixes indicate the complete polymerization [6]. The shift appears for $\mathrm{C}-\mathrm{O}$ ester in all PMMA matrixes to lower wave number with increasing the percentage of ST provides evidence of complete copolymerization. The shift occurring in $\mathrm{C}=\mathrm{O}$ ester in homo PMMA and copolymers to higher wave number indicating amphoteric nature of this matrix [7]. The appearance of $-\mathrm{N}=\mathrm{N}-\left(1460-1400 \mathrm{~cm}^{-1}\right)$ and $\mathrm{C}-\mathrm{H}$ band of aromatic ring $\left(750 \mathrm{~cm}^{-1}\right)$ for ponceau

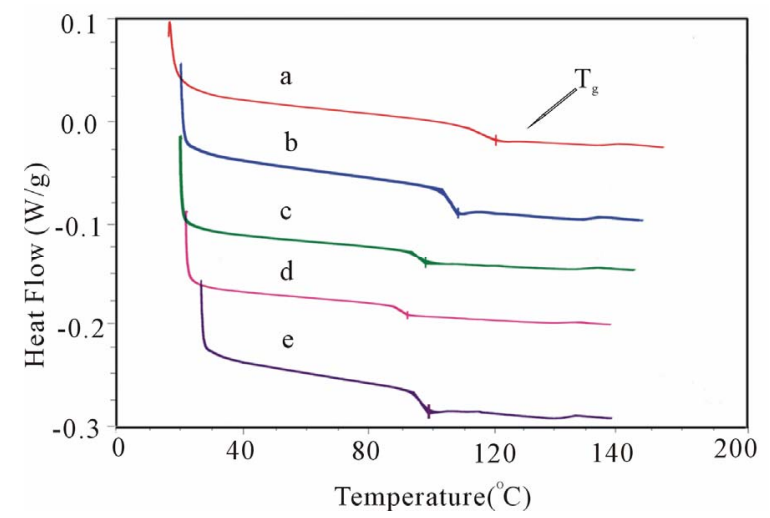

Figure 2. The DSC of ponceau 2R in PMMA (a); ST-COMMA (30/70) (b); ST-CO-MMA (50/50) (c); ST-CO-MMA (70/30) (d) and PS (e). 
2R in all LSCs indicating that the highest stability of this kind of dye in this matrixes. Also, the intensity of this band increases with increasing the percentage of ST. These results refer to miscibility of the dye in all matrixes and all of them act as inert medium.

\subsection{Spectroscopic Properties}

\subsubsection{The Photostability of LSCs}

The change of absorption maxima of ponceau $2 \mathrm{R}$ in all matrixes versus irradiation time are shown in Figure 4. It is clear that for all polymer/ponceau 2R LSCs the optical density of the dye upon exposure to the sun light is decreased by increasing exposure time. The observed decrease in absorbance value can be attributed to photochemical decomposition of the dye as a result of absorption of the solar radiation.

The percentage of optical density changes of the dye was calculated from the relation [8]:

$$
p \%=\frac{A_{t}}{A_{o}} \times 100 \%
$$

where $A_{t}$ : the maximum absorption after exposure the sun light for (18 hours), A: the maximum absorption before irradiated and $\mathrm{P} \%$ : the percentage of ponceau $2 \mathrm{R}$ remains after (18 hours). From Figure 5 we notice that the percent of the dye increases in the following order:

$$
\begin{aligned}
& \text { ST-CO-MMA }(70-30)<\text { PS < ST-CO-MMA }(50-50) \\
& <\text { ST - CO-MMA }(30-70)<\text { PMMA }
\end{aligned}
$$

These results may be due to an electron transfer from the dye molecule to the main of PMMA chain during the transfer from excited state to ground state $S_{1}-S_{0}$ molecules.

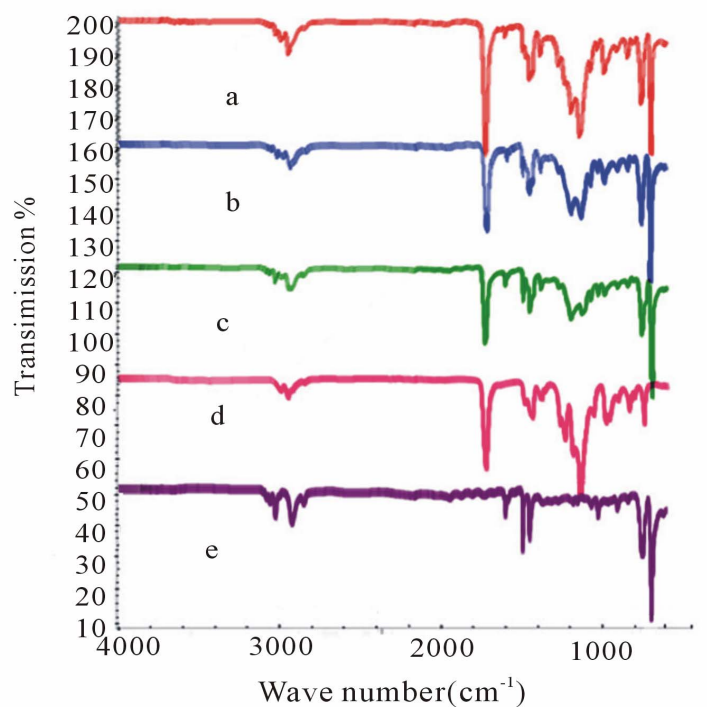

Figure 3. The FTIR spectra of Ponceau 2R in PMMA (a); ST-CO-MMA (30/70) (b); ST-CO-MMA (50/50) (c); ST-COMMA (70/30) (d) and PS (e).
This behavior means that the isolation of the trapped molecules from deactivation bimolecular processes, and the rigidity of the surroundings, is reflected in photostability. This indicates that PMMA is making the dye less sensitive to light [6].

The kinetics of the photodegrdation of polymer/ponceau 2R LSCs through exposure to sunlight have been studied by following the change in intensity of absorption at their absorption maxima. The degradation process was found to obey a first-order kinetic equation in which:

$$
\ln \frac{A_{o}}{A_{t}}=k t
$$

where $k$ is first order rate constant, $A_{o}$ and $A_{t}$ are the absorbance at time $t=0$ and $t=t$ (hour) respectively. The first-order kinetic equation plots $\ln \left(A_{o} / A_{t}\right)$ vs. $t$ for ponceau $2 \mathrm{R} / \mathrm{LSCs}$ are shown in Figure 6. From the slope of these curves the rate of photodegrdation was calculated and listed in Table 1. From this Table it is clear that the rate of degradation was found to follow the order:

$$
\begin{aligned}
& \text { ST-CO-MMA (70-30) > PS > ST-CO-MMA (50-50) } \\
& >\text { ST-CO-MMA (30-70) > PMMA }
\end{aligned}
$$

The obtained results show that the rate of degradation is increased from lower rate degradation $\left(0.21 \mathrm{~h}^{-1}\right)$ for $\mathrm{PMMA} /$ ponceau $2 \mathrm{R}$ to large degradation rate value (1.5 $\mathrm{h}^{-1}$ ) for ST-CO-MMA $(70-30) /$ ponceau 2R. The lower degradation rate of ponceau $2 \mathrm{R}$ in homo PMMA matrix

\begin{tabular}{|c|c|c|c|c|}
\hline Samples & $\begin{array}{c}\text { Exposure } \\
\text { time (week) }\end{array}$ & $E_{g}(\mathrm{eV})$ & $E_{u}(\mathrm{eV})$ & $k\left(\mathrm{hr}^{-1}\right)$ \\
\hline $\begin{array}{c}\text { PMMA } \\
\text { (0ST-100MMA) }\end{array}$ & $\begin{array}{l}0 \\
9\end{array}$ & $\begin{array}{l}1.92 \\
1.88\end{array}$ & $\begin{array}{l}0.25 \\
0.28\end{array}$ & 0.21 \\
\hline $\begin{array}{c}\text { ST-CO-MMA } \\
(30 \mathrm{ST}-70 \mathrm{MMA})\end{array}$ & $\begin{array}{l}0 \\
7\end{array}$ & $\begin{array}{l}1.78 \\
1.82\end{array}$ & $\begin{array}{l}0.34 \\
0.29\end{array}$ & 0.27 \\
\hline $\begin{array}{c}\text { ST-CO-MMA } \\
(50 \mathrm{ST}-50 \mathrm{MMA})\end{array}$ & $\begin{array}{l}0 \\
2\end{array}$ & $\begin{array}{l}1.92 \\
1.98\end{array}$ & $\begin{array}{l}0.47 \\
0.29\end{array}$ & 0.28 \\
\hline $\begin{array}{c}\text { ST-CO-MMA } \\
(70 \mathrm{ST}-30 \mathrm{MMA})\end{array}$ & $\begin{array}{l}0 \\
2\end{array}$ & $\begin{array}{l}2.1 \\
2.0\end{array}$ & $\begin{array}{l}0.26 \\
0.25\end{array}$ & 1.50 \\
\hline $\begin{array}{c}\text { ps } \\
(100 \mathrm{ST}-0 \mathrm{MMA})\end{array}$ & $\begin{array}{l}0 \\
2\end{array}$ & $\begin{array}{l}1.84 \\
1.76\end{array}$ & $\begin{array}{c}0.5 \\
0.53\end{array}$ & 0.30 \\
\hline
\end{tabular}
indicates that the use of this matrix to manufacture luminescent solar collectors.

Table 1. The optical parameters $\left(E_{g}\right.$ and $\left.E_{u}\right)$ and specific rate of degradation for polymer/dye samples upon exposure to sunlight. 


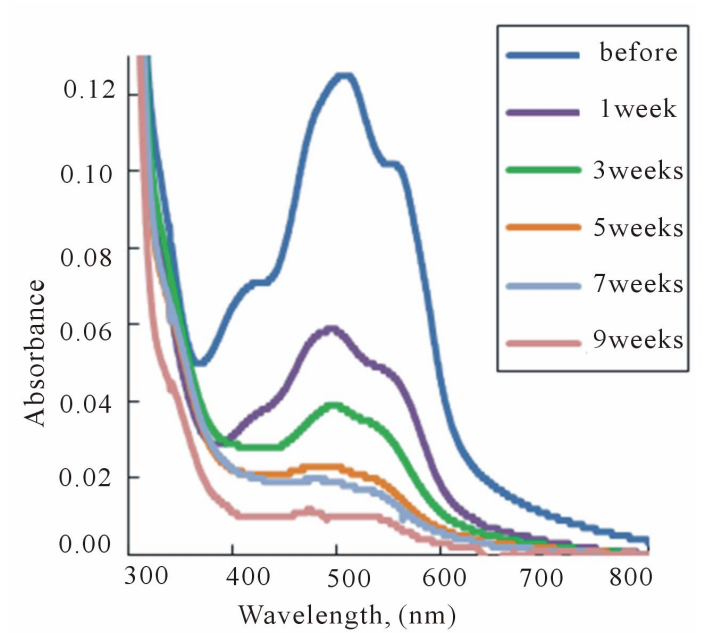

(a)

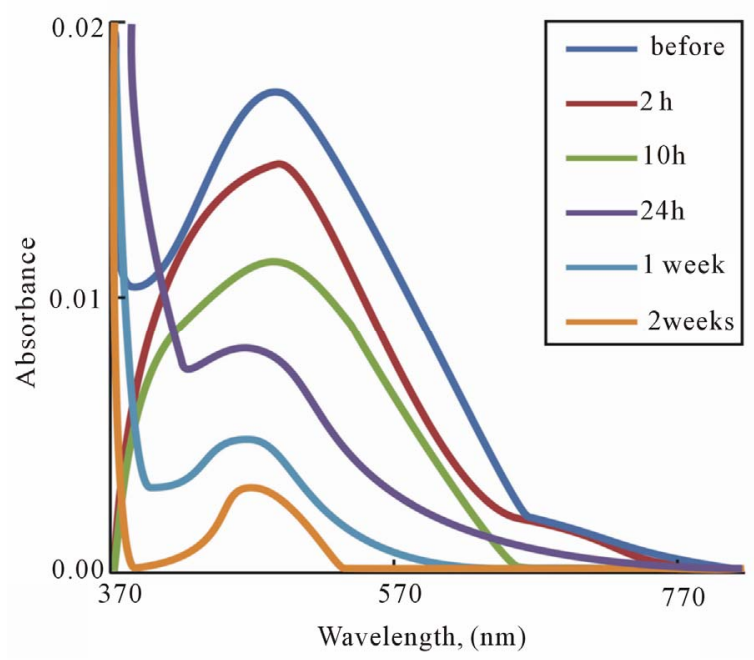

(c)

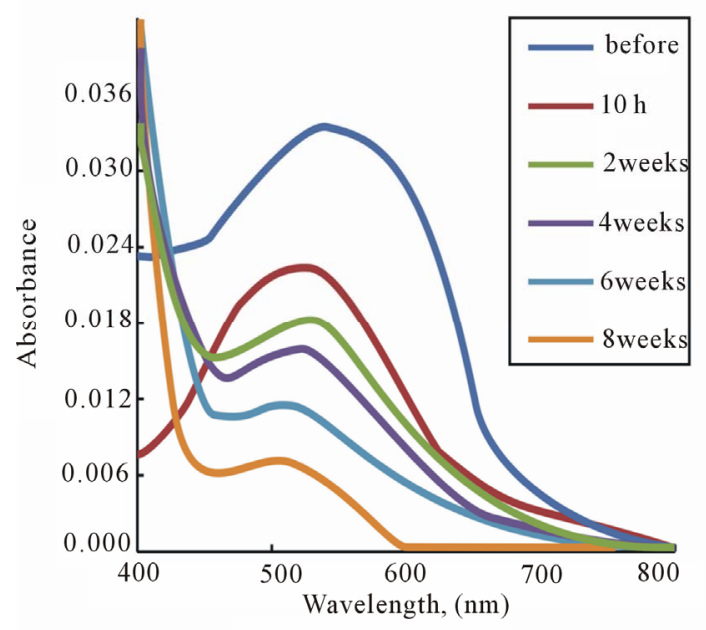

(b)

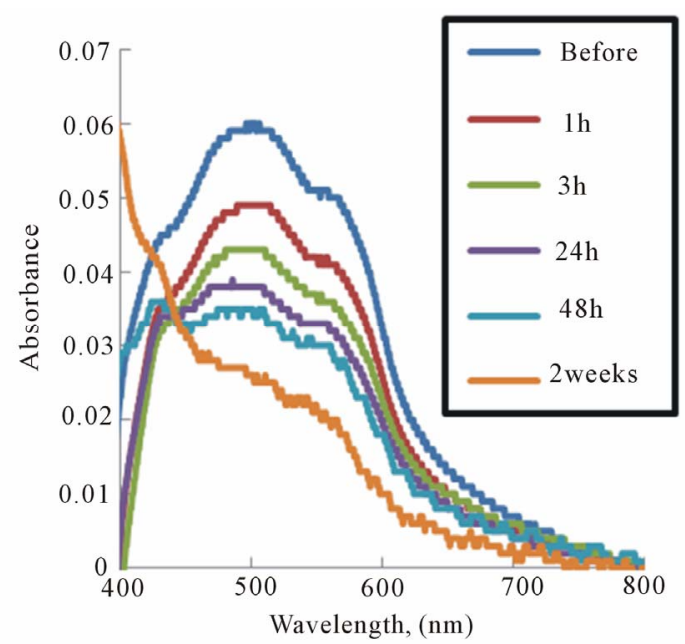

(d)

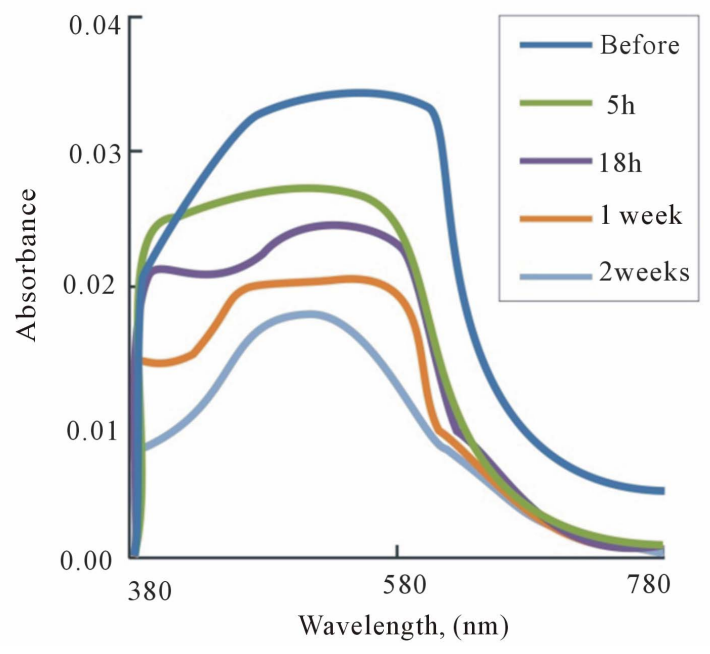

(e)

Figure 4. The change in absorbance for ponceau 2R in PMMA (a); ST-CO-MMA (30/70) (b); ST-CO-MMA (50/50) (c); ST-CO-MMA (70/30) (d) and PS (e). 


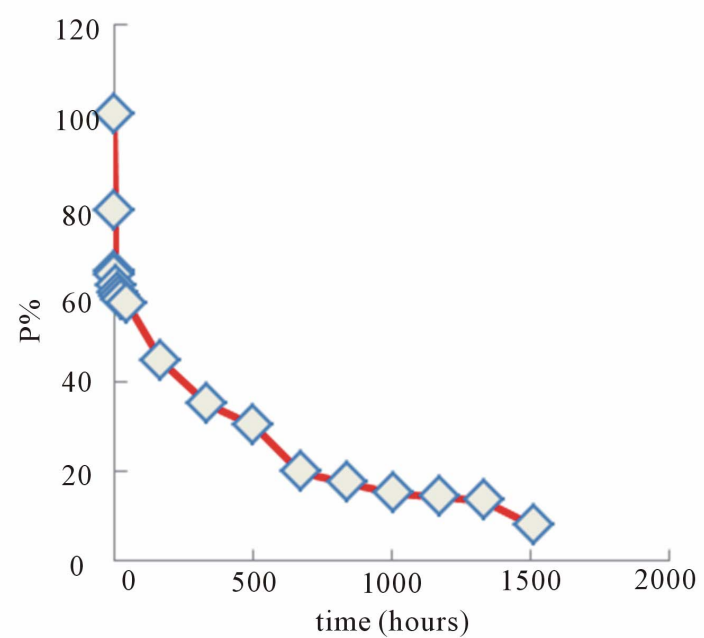

(a)

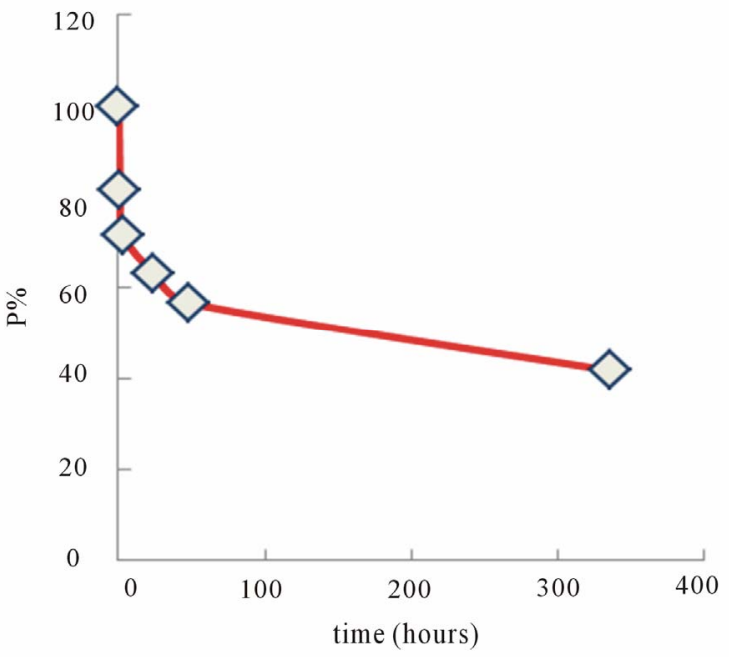

(c)

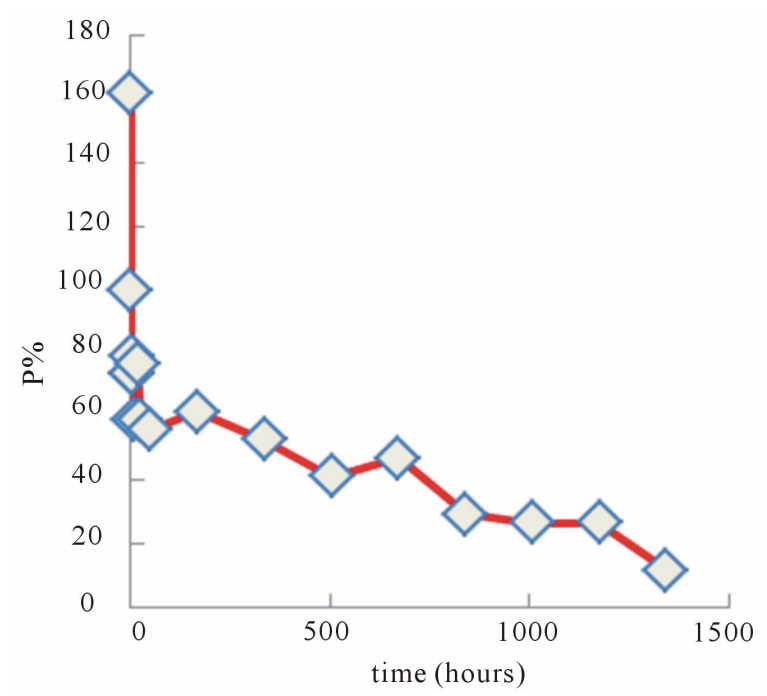

(b)

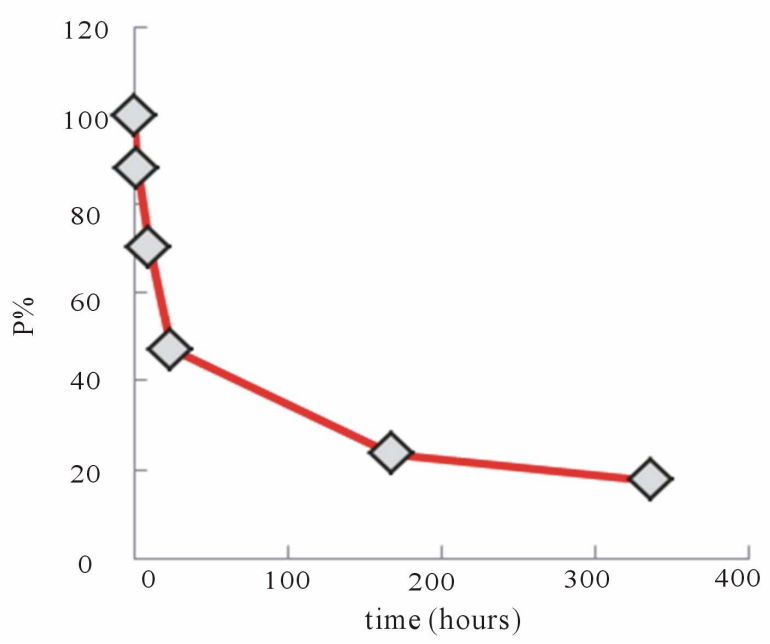

(d)

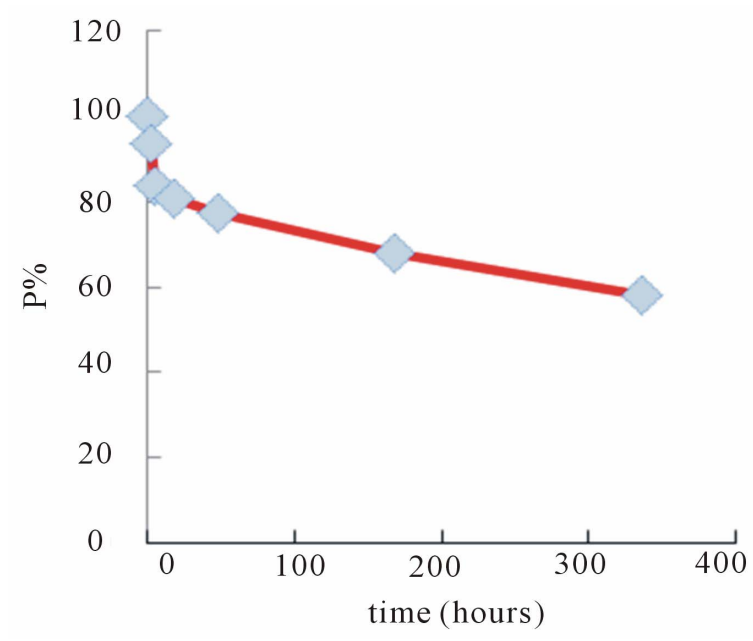

(e)

Figure 5. The photodegrdation of Ponceau 2R in PMMA (a); ST-Co-MMA (30/70) (b); ST-Co-MMA (50/50) (c); ST-CoMMA (70/30) (d) and PS (e). 


\subsubsection{Optical Measurements}

The absorption coefficient $(\alpha)$ can be expressed by the relation [4]:

$$
\alpha(h v)=2.3\left\{\frac{\log \left(I / I_{o}\right)}{d}\right\}=2.3 \frac{A}{d}
$$

where $I_{o}$ and $I$ are the intensity of the incident and transmitted light; $A$ is the absorbance; and $d$ is the film thickness depends on the transition type. Figure 7 shows the dependence of $(\alpha E)^{2}$ on photon energy $E$ for all polymer/ponceau 2R LSCs before and after exposure to sun light. The relation has a linear behavior that can be considered as evidence of the direct transition (i.e. for $n$ $=1 / 2$ ). The approximate value of the band gap energy can be determined from the extrapolation of the straight-line part to zero photon energy. These values are listed in Table 1. From these values it is clear that the $E_{g}$ of LSCs varied from one matrix to another. The higher optical band gap seems to be related to the PMMA matrix and its width changes due to the induced energy states from the symmetrical field of ST. Increasing ST content may cause the localized states of different centers to overlap and extended in the mobility gap of PMMA. This over lapping evidence for decreasing energy gap when ST content is increased in the PMMA matrix. The lower absorption edge for all matrixes evidence the presence of another type of induced states depending on the doping level of dye [7]. This may be due to differ intersect the dye in matrix and consequence increase the degree of disorder in amorphous structure. On the other hand, the change in $E_{g}$ values after exposure to sun light in sample of PMMA/ponceau $2 \mathrm{R}(2 \%)$ is lower compared with other matrixes, which means that the homopolymers is a good base matrix for laser dyes and has high photo-stability.

Urbach [4] assumed that the absorption coefficient $(\alpha)$ near the band edge shows exponential dependence on photon energy $(E)$ according to the following relation:

$$
\alpha=\alpha_{o} \exp \left(\frac{E}{E_{u}}\right)
$$

where $E_{u}$ is the Urbach's energy corresponding to the width of band tails of the localized states in the band gap. The Urbach energy $\left(E_{u}\right)$ values were calculated as the reciprocal gradient of the straight line obtained from the relation between $\ln \alpha$ versus the photon energy $(E)$ as shown in Figure 8. The results are summarized and listed in Table 1. The obtained results show that, by increasing ST content, the band tail widths move to high values due to increase defect in the forbidden gap. The values of $E_{u}$ decreases by increasing exposure time due to the degradation of the dye. These results indicate that the increase ST content decrease the stability of dye.

\section{Fluorescence Measurements}

In order to give more information on the efficiency of the solar collectors for our investigated samples the fluorescence properties of these LSCs were investigated. Figure 9 shows the emission spectra of our investigated samples. The fluorescence intensity follows the following order:

$$
\text { PMMA > ST-CO-MMA(30-70) > ST-CO-MMA (50-50) }
$$$$
>\text { ST-CO-MMA (70-30) > PS }
$$

This indicates that PMMA/ponceau $2 \mathrm{R}$ has the highest fluorescence intensity; therefore it is selected to be used as fluorescent solar collectors. It is clear the fluorescence intensity of the dye was decreased with increasing the percentage of ST. This may be attributed to increase ST content increase the plasticizing properties of matrix so the collisions between the dye molecules are be possible $[8,9]$. The fluorescent emission spectra of these samples after exposure to sunlight are shown in Figure 10. It is found that fluorescent intensity of ponceau $2 \mathrm{R}$ is decreased after exposure to sun light in PMMA and STCO-MMA (30-70) due to bleach the dye. Also, it is found that fluorescent intensity of the dye is increased after exposure to sunlight in ST-CO-MMA (50-50), ST-CO-MMA (70-30) and PS. The dye show the emission band at longer wavelength (red shift) in homo PMMA and PS matrixes and at short wavelength in ST-CO-MMA (50-50), ST-CO-MMA (30-70). This indicates that self-absorption of the emitted radiation is increased for the ponceau $2 \mathrm{R}$ after exposure to sunlight in the last matrix. The new band appear at shorter wavelength was due to eximer formation that exist only in the excited state; the eximer is weakly fluorescent.

The Stokes shift $(\Delta \lambda)$, which is the difference between the wavelength at which the absorption and emission maxima are observed, is presented in Table 2. It can be seen that Stokes shift increase by increasing the ST content. This is indicative of a lower self-absorption of the radiation emitted by the ponceau $2 \mathrm{R}$ molecules in these matrixes. The Stokes shift depends on the polarity of the medium, decreasing the content of non polar ST increase polarity of matrix and so affect on the value of Stokes shift.

The ability of molecules to emit the absorbed light energy is characterized quantitatively by the quantum fluorescence yield $\left(Q_{f}\right)$, which can be defined as the ratio of total energy emitted per quantum of energy absorbed. The fluorescence quantum yield can be calculated from the following equation [7]:

$$
Q_{f}=Q_{r e f} \times \frac{a_{r e f}}{a_{\text {sam }}} \times \frac{A_{\text {smp }}}{A_{\text {ref }}} \times\left(\frac{n_{\text {sam }}}{n_{\text {ref }}}\right)^{2}
$$

where $Q_{r e f}$ is the fluorescence quantum yield of a reference 


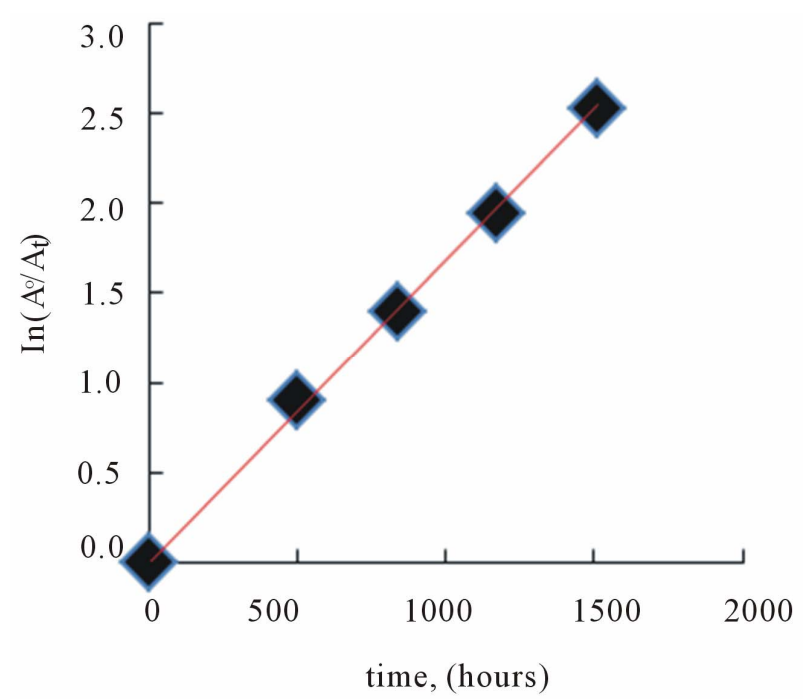

(a)

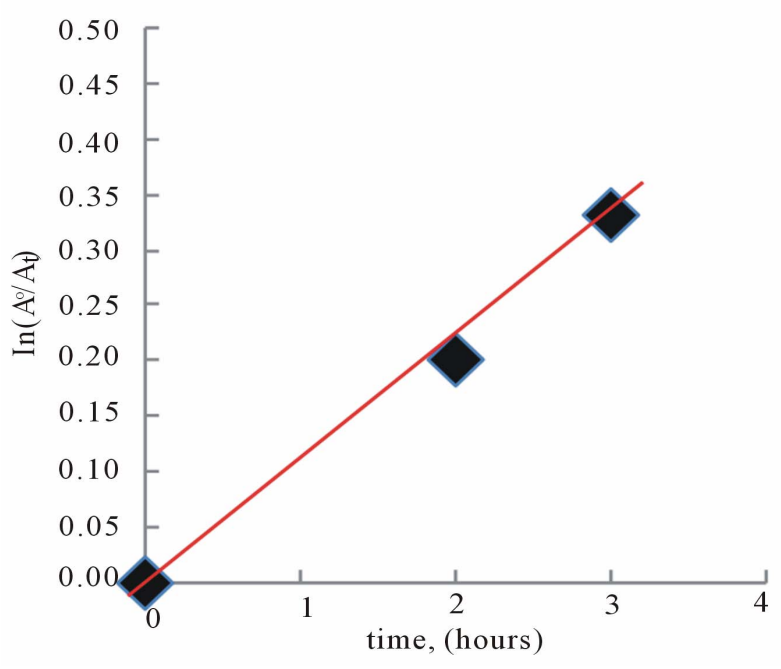

(c)

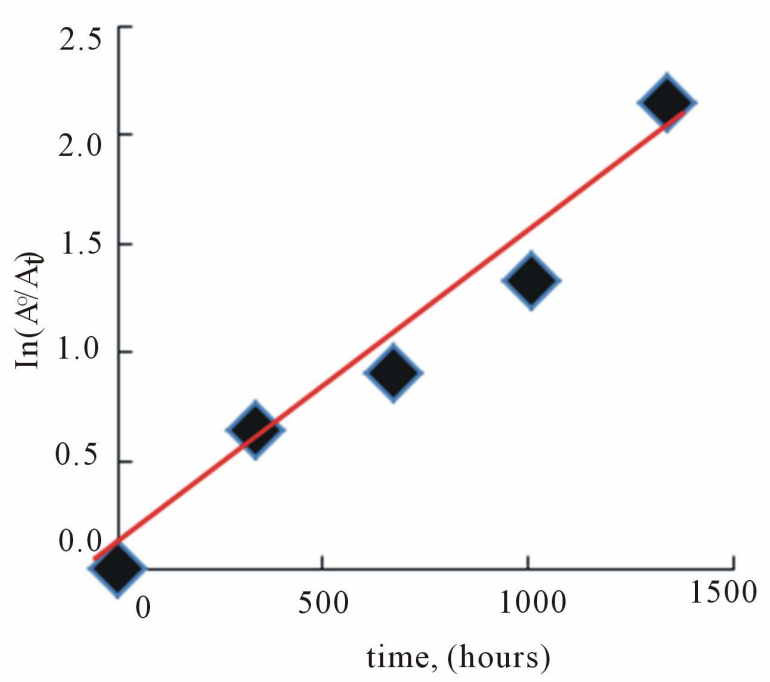

(b)

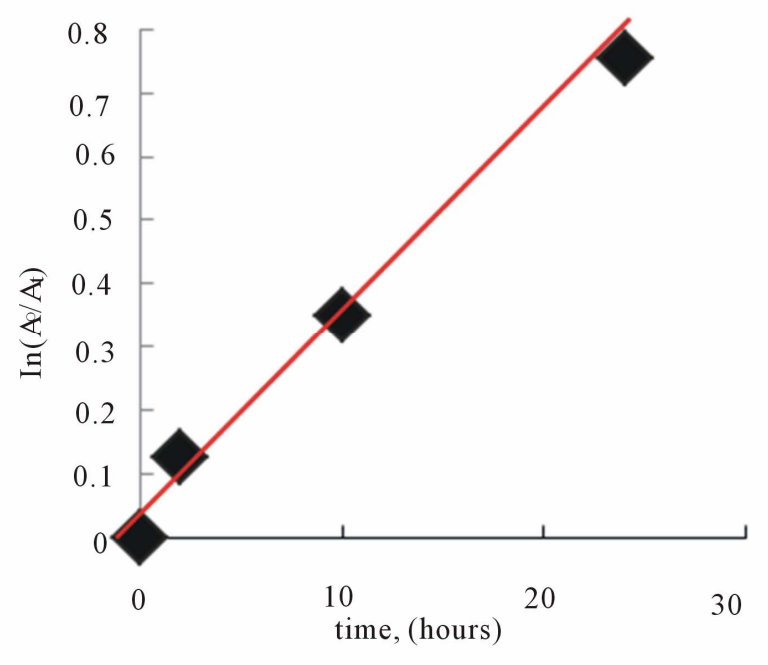

(d)

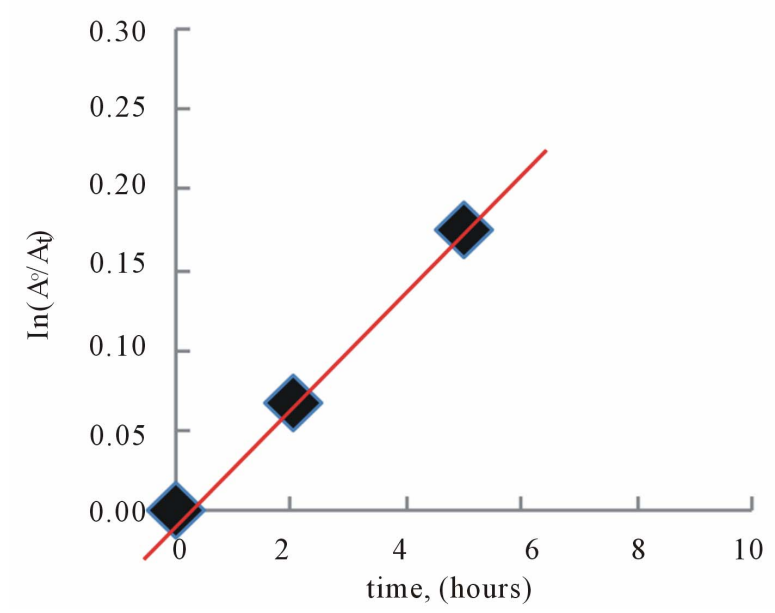

(e)

Figure 6. The first order kinetic equation plots for degradation of ponceau 2R in PMMA (a); ST-CO-MMA (30/70) (b); ST-CO-MMA (50/50) (c); ST-CO-MMA (70/30) (d) and PS (e). 
(quinine sulphate $=0.55) . A_{s a m}$ and $A_{r e f}$ are the areas under the fluorescence spectrum, $a_{\text {sam }}$ and $a_{\text {ref }}$ are the absorbance at excitation wavelength, $n_{\text {sam }}$ and $n_{\text {ref }}$ are the refractive indices of the solvent and reference, respectively. The values of $Q_{f}$ before and after exposure to sun light

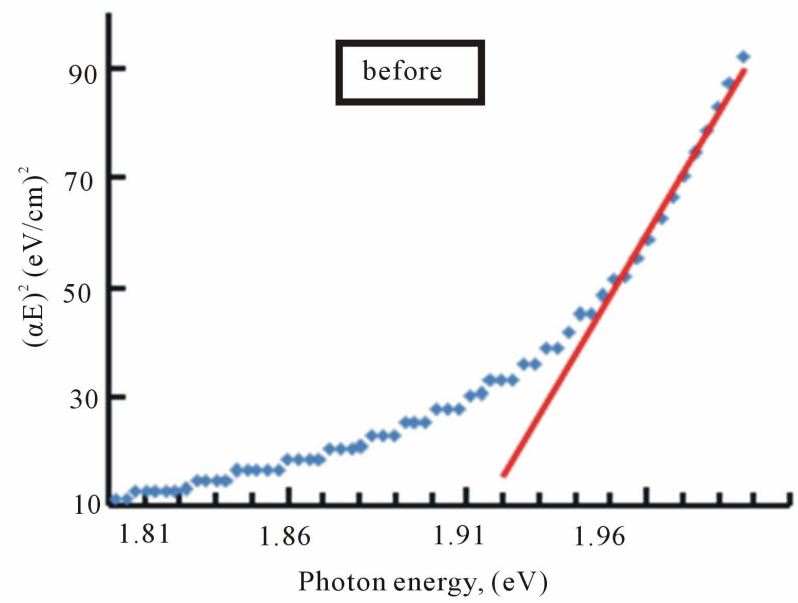

(a)

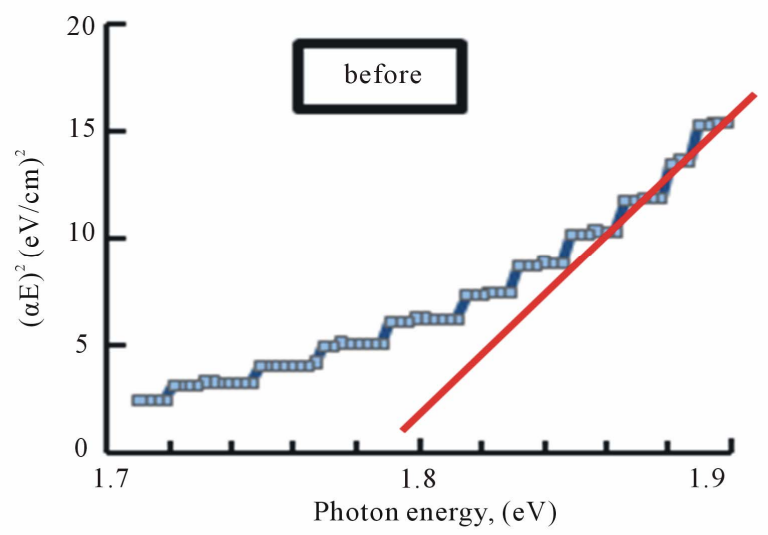

(b)

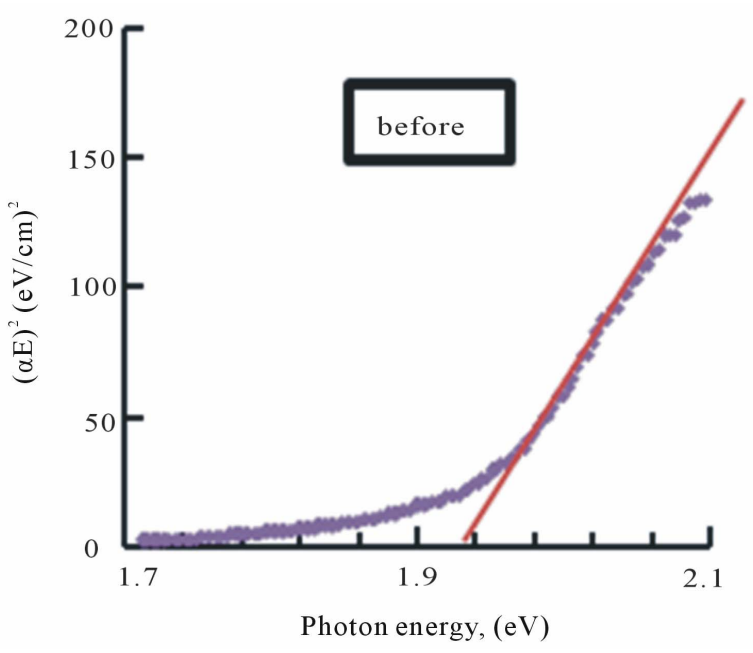

are listed in Table 2. This Table reveals that the dye has the highest $Q_{f}$ in PMMA. The higher values of $Q_{f}$ in the PMMA matrix are due to the its rigidity (as confirmed by DSC). It is clear that the fluorescence intensity of the dye was decreased with increasing the percentage of ST,
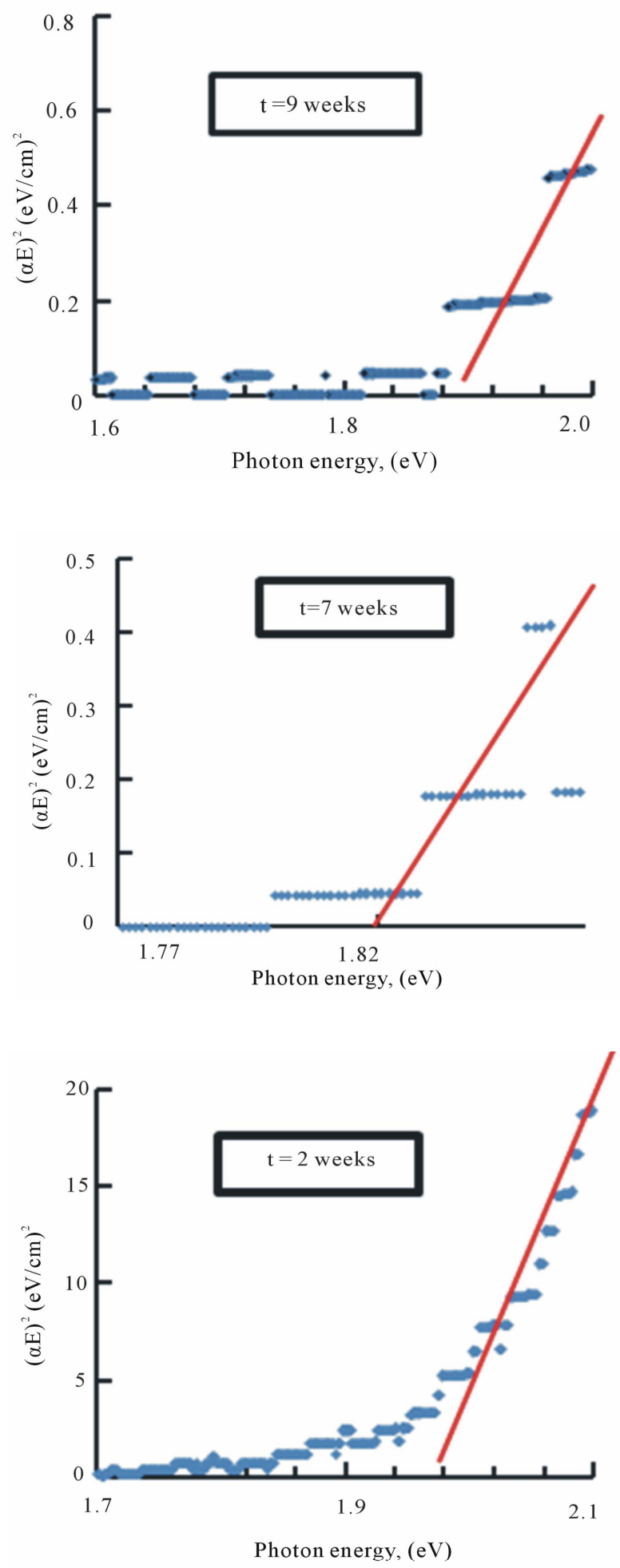

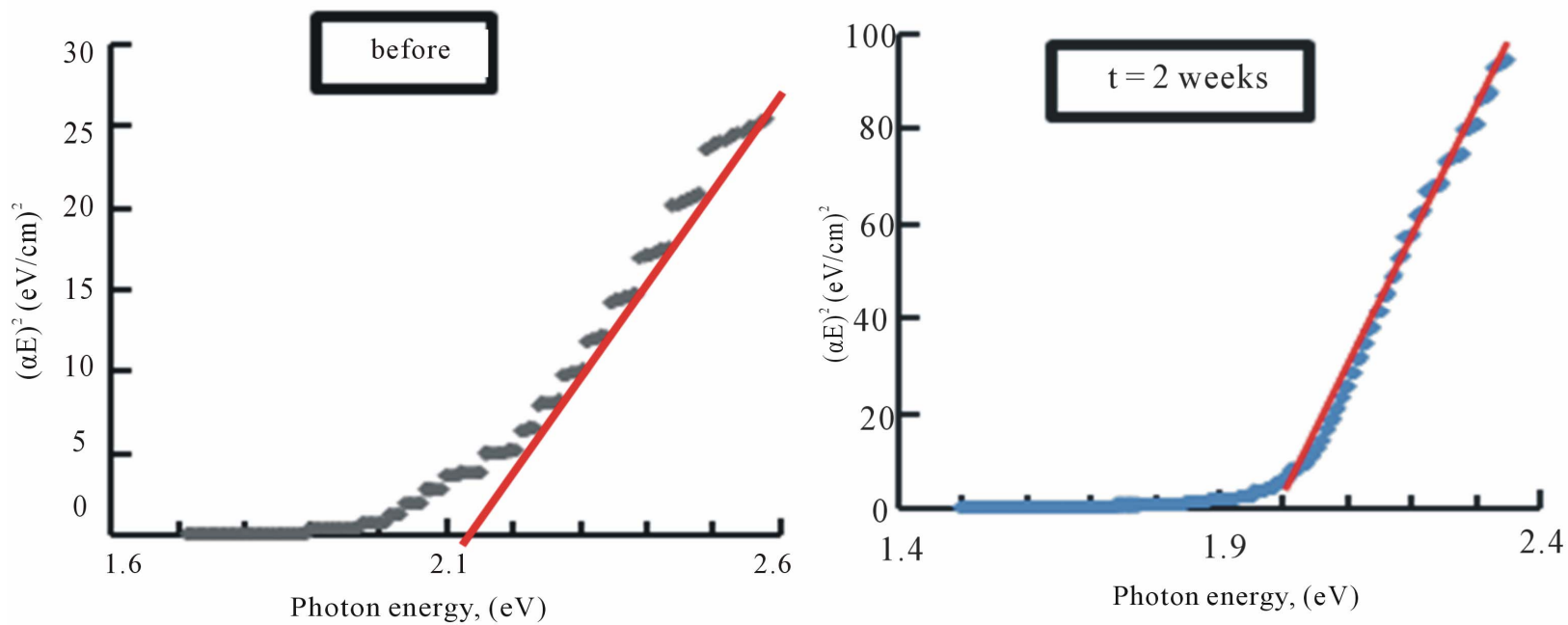

(d)

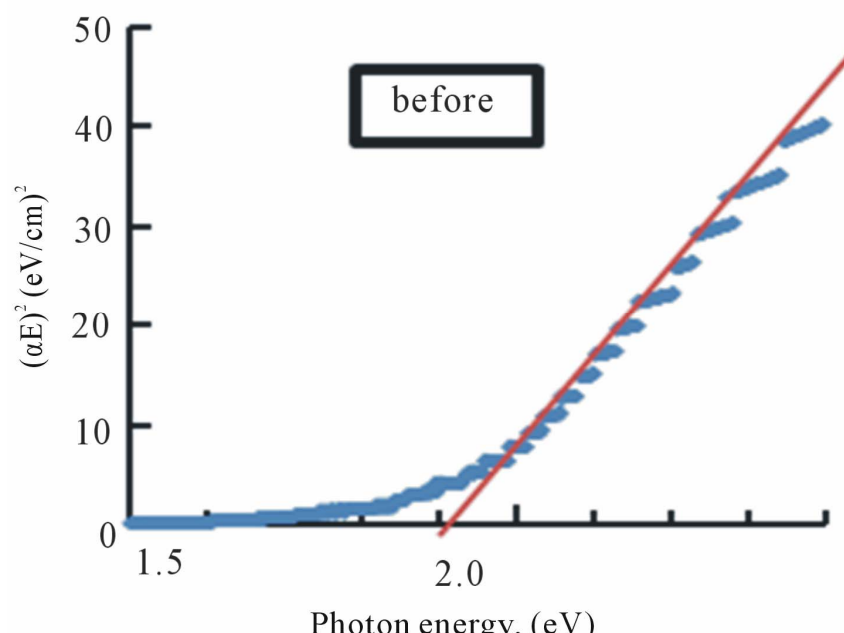

Photon energy, $(\mathrm{eV})$

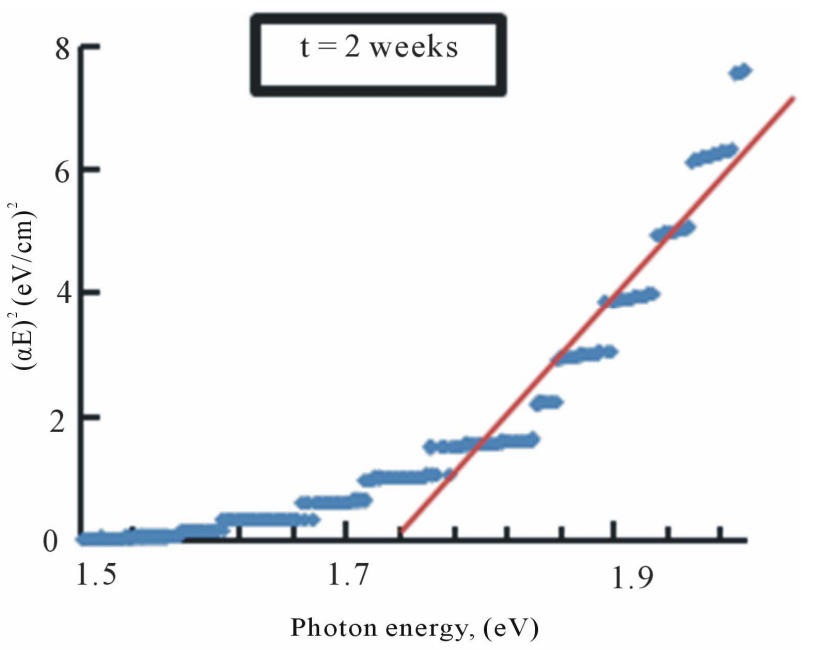

e)

Figure 7. The dependence of $(\alpha E)^{2}$ on photon energy for ponceau 2R in PMMA (a); ST-CO-MMA (30-70) (b); ST-CO-MMA (50-50) (c); ST-CO-MMA (70-30) (d) and PS (e) before and after exposure to sunlight.

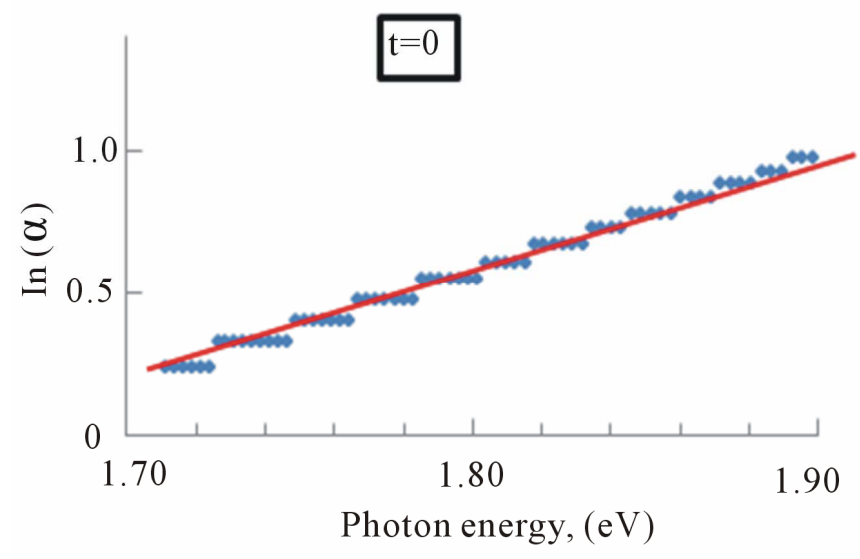

(a)

a)

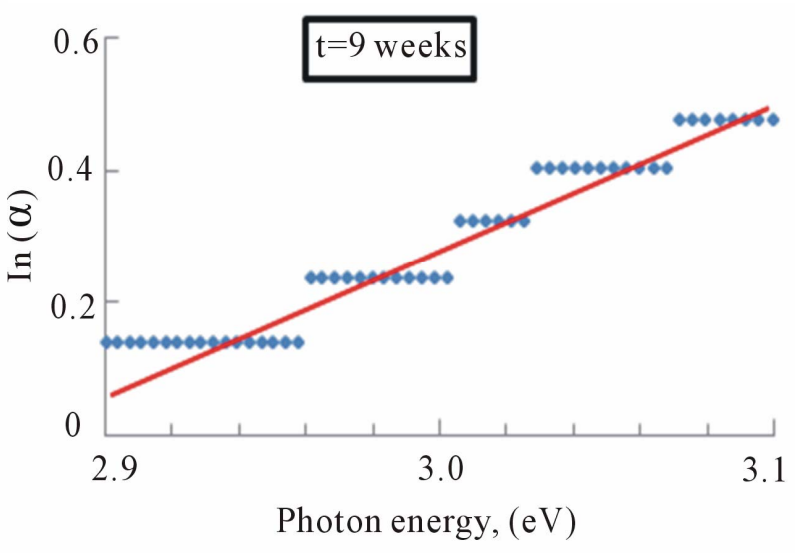



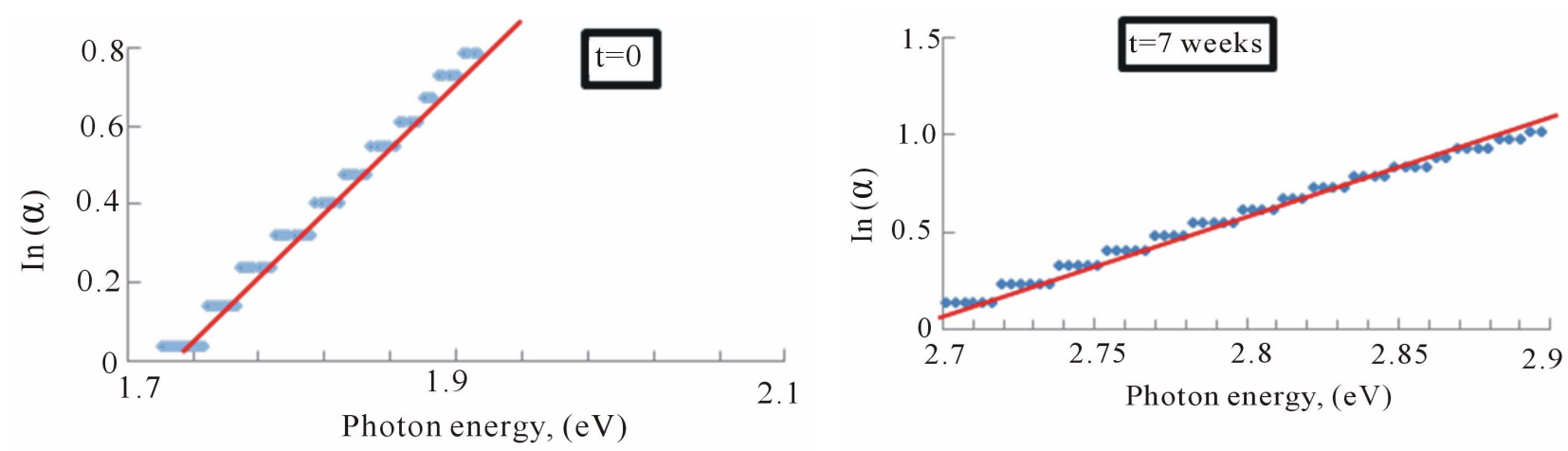

(b)
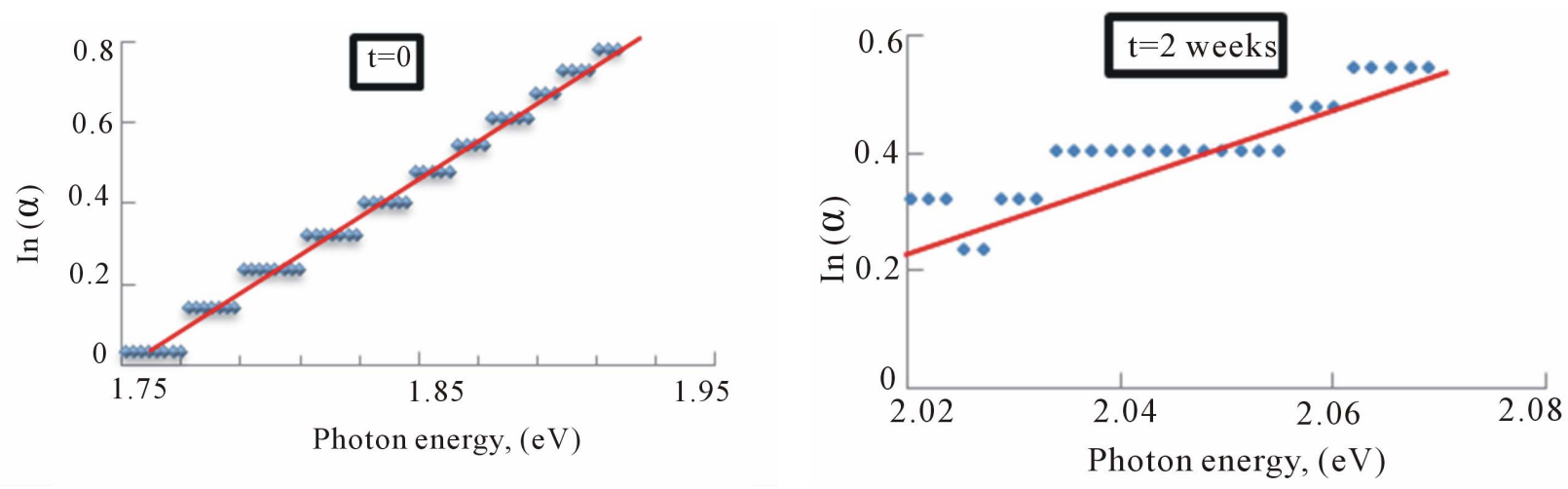

(c)
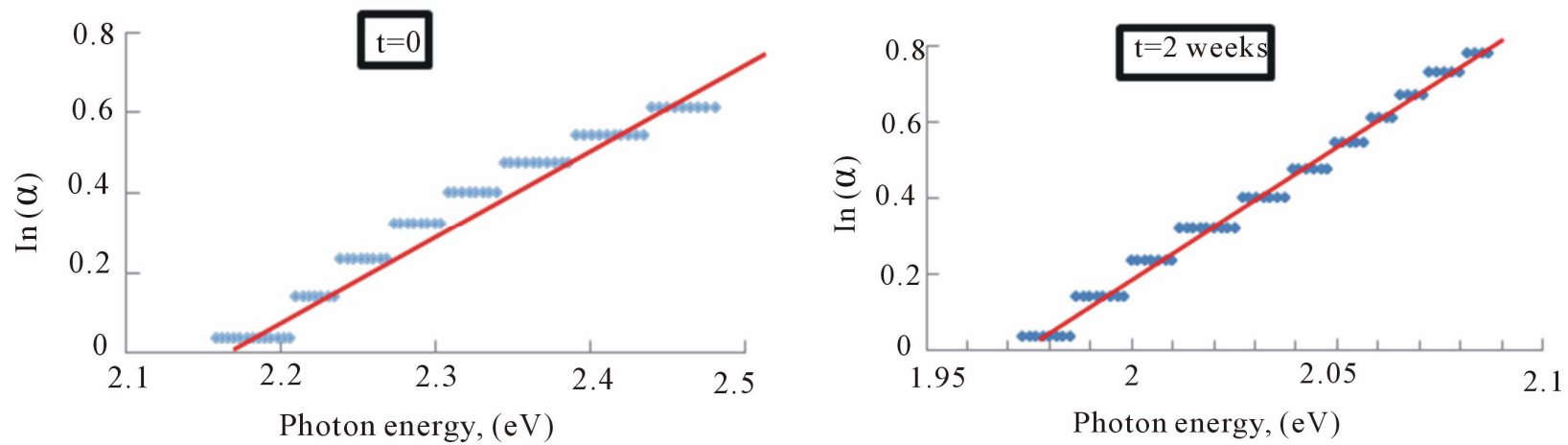

(d)
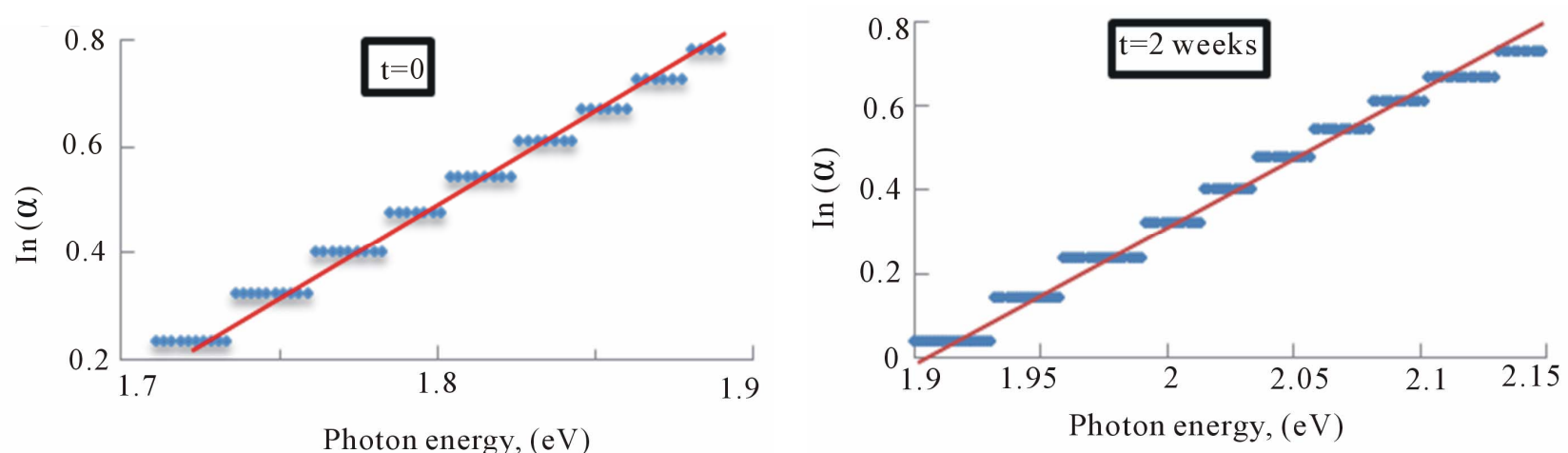

(e)

Figure 8. The variation of $\ln (\alpha)$ vs photon energy for ponceau $2 \mathrm{R}$ prepared by casting method in PMMA (a); ST-Co-MMA (30/70) (b); ST-Co-MMA (50/50) (c); ST-Co-MMA (70/30) (d) and PS (e) before and after exposure to sunlight. 


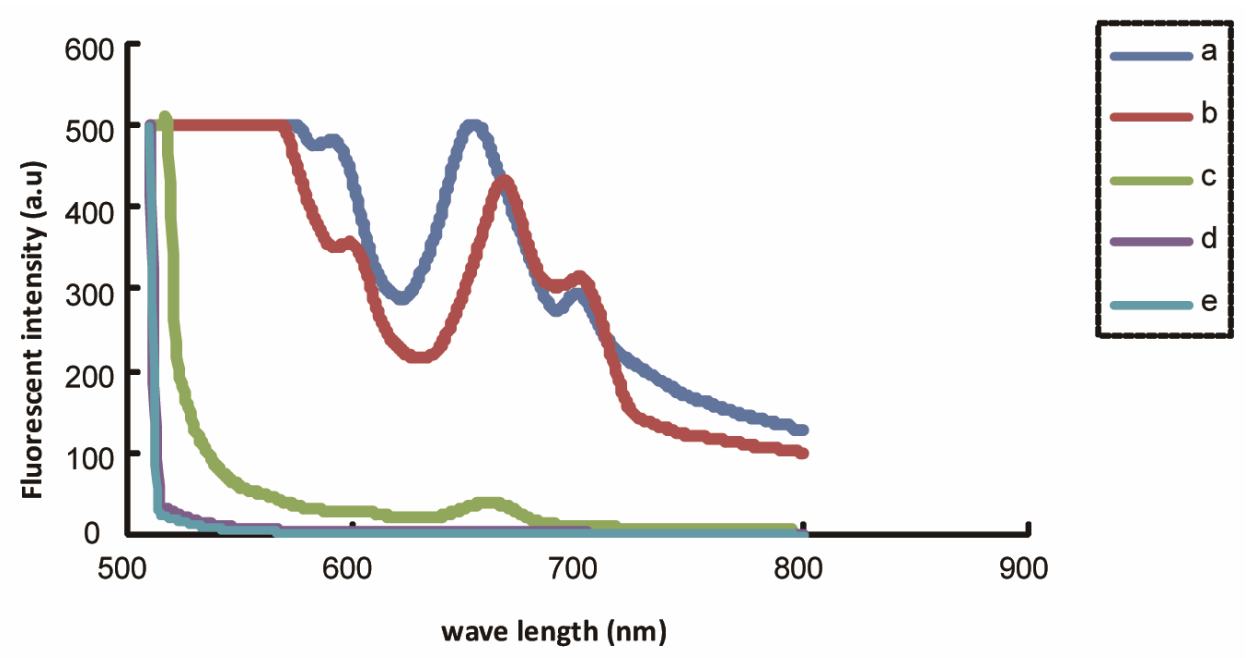

Figure 9. The Fluorescence spectra of ponceau 2R in PMMA (a); ST-CO-MMA(30-70) (b); ST-CO-MMA(50-50) (c); STCO-MMA (70-30) (d) and PS (e) before expouser sunlight.

because increasing the plasticizing properties of matrix so the collisions between the dye molecules are be possible in this type of matrix [9]. Thus, elimination of translational freedom of the molecules is achieved and deactivation of excited molecules by intermolecular collision is avoided. Therefore homo PMMA can be selected for field performance of fluorescent solar collectors.

\section{Efficiency of Photovoltaic Cell Coupled with PMMA/2R LSC}

The current-voltage characteristics of the photovoltaic cell using PMMA/ponceau 2R LSC under direct sun light $\left(850 \mathrm{~W} / \mathrm{m}^{2}\right)$ are shown in Figure 11. The open circuit voltage $\left(V_{o c}\right)$ and short circuit current $\left(I_{s c}\right)$ were obtained from $x$ and $y$ intercepts, respectively. The fill factor was calculated using the following relation [10]:

$$
F F=\frac{V_{m} I_{m}}{V_{o c} I_{s c}}
$$

where $V_{m}$ and $I_{m}$ are voltage and current respectively, for maximum power output. The overall energy conversion yield $(\eta)$ was defined as the following relation:

$$
\eta=\frac{I_{s c} V_{o c} F F}{P_{i n}}
$$

where $P_{\text {in }}$ is the power of the incident white light. The values of fill factor $(F F)$ and efficiency $(\eta)$ were calculated and given in Table 3. As shown in Table 3, the photovoltaic cell coupled with LSC shows a maximum efficiency, $2 \%$ compared to the normal one. This indicates the PMMA/ponceau 2R LSC increase efficiency of photovoltaic cell due to its high photostbility and luminescent properties. Also, the ability of LSC to collect both the diffuse and direct sun light.
Table 2. The Stokes shift $(\Delta \lambda)$ and fluorescence quantum yield $\left(Q_{f}\right)$ for polymer/dye samples.

\begin{tabular}{cccccc}
\hline Samples & $\begin{array}{c}\text { Exposure } \\
\text { time } \\
(\text { week })\end{array}$ & $\begin{array}{c}\lambda_{\text {abs }} \\
(\mathrm{nm})\end{array}$ & $\begin{array}{c}\lambda_{e m} \\
(\mathrm{~nm})\end{array}$ & $\begin{array}{c}\Delta \lambda \\
(\mathrm{nm})\end{array}$ & $Q_{f}$ \\
\hline PMMA & 0 & 510 & 658 & 148 & 0.20 \\
$\begin{array}{c}\text { (OST-100 } \\
\text { MMA) }\end{array}$ & 9 & & 663 & 153 & 0.04 \\
ST-CO-M & & & & & \\
MA & 0 & 517 & 667 & 150 & 0.14 \\
(30ST-70 & 7 & & 655 & 148 & 0.07 \\
MMA) & & & & & \\
ST-CO-M & & & & & \\
MA & 0 & 503 & 665 & 162 & 0.1 \\
(50ST-50 & 2 & & - & - & - \\
MMA) & & & & & \\
ST-CO-M & & & & & \\
MA & 0 & 467 & 662 & 195 & 0.05 \\
(70ST-30 & 2 & & 664 & 194 & 0.09 \\
MMA) & & & & & \\
ps & & & & & \\
(100ST-0 & 0 & 512 & 678 & 166 & 0.03 \\
MMA) & 2 & & 686 & 174 & 0.05 \\
\hline
\end{tabular}

\section{Conclusion}

In this paper we prepare some LSCs using PMMA/PS as a matrixe doped with ponceau 2R. Copolymer films from different percentages from ST/MMA doped with ponceau 2R have been prepared. DSC shows PMMA/ Ponceau $2 \mathrm{R}$ LSC has $T_{g}=122^{\circ} \mathrm{C}$, providing evidence of thermal stability of the homo PMMA LSC. FTIR spectra were obtained to give information on the characteristic bands of the homo and copolymer LSCs. The photo stability of these polymer-dye mixed samples were studied under outdoor exposure to sunlight at different times. The results indicate that the degradation of these 


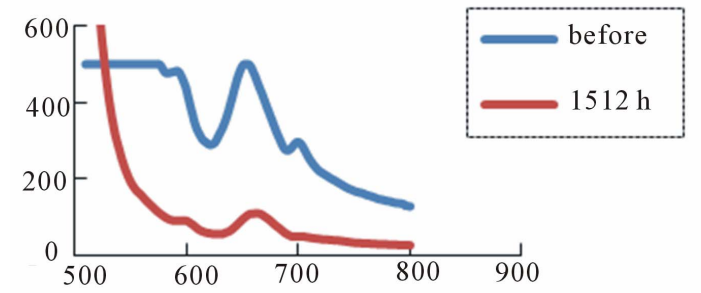

(a)

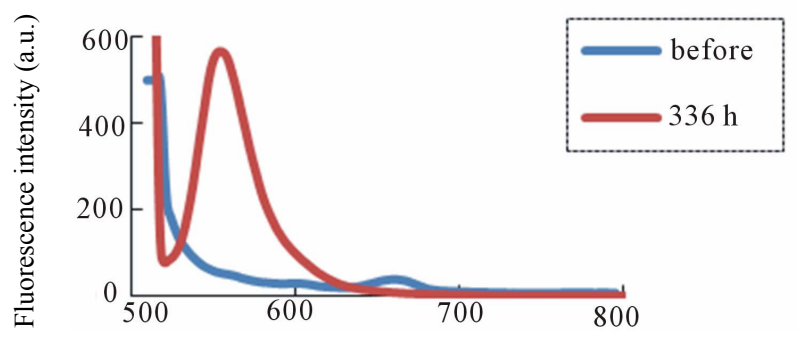

(c)

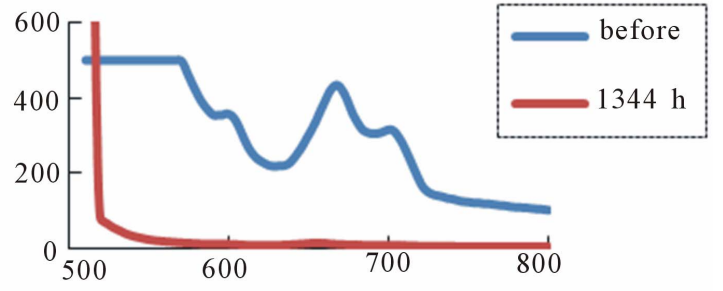

(b)

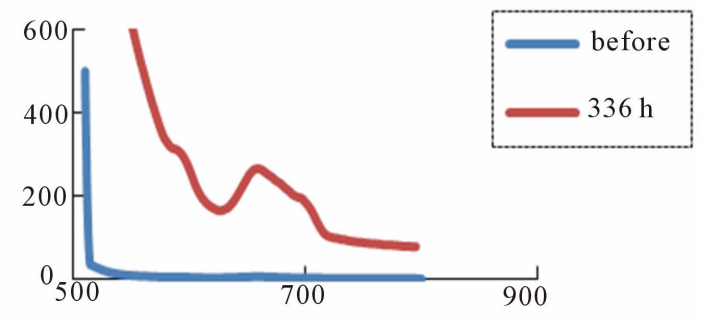

(d)

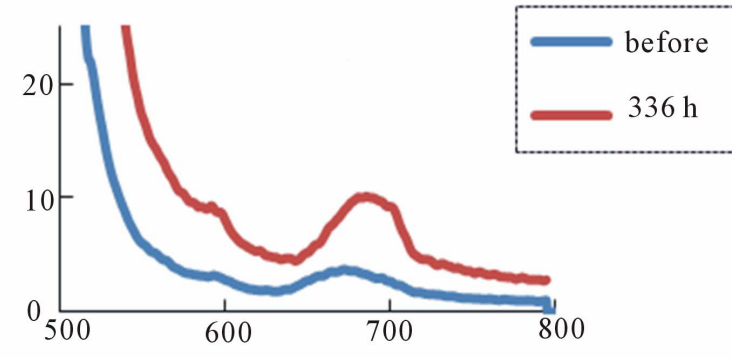

(e)

Wavelength (nm)

Figure 10. The Fluorescence spectra of ponceau 2R in PMMA (a); ST-CO-MMA (30-70) (b); ST-CO-MMA (50-50) (c); ST-CO-MMA (70-30) (d) and PS (e) before and after expouser sunlight.

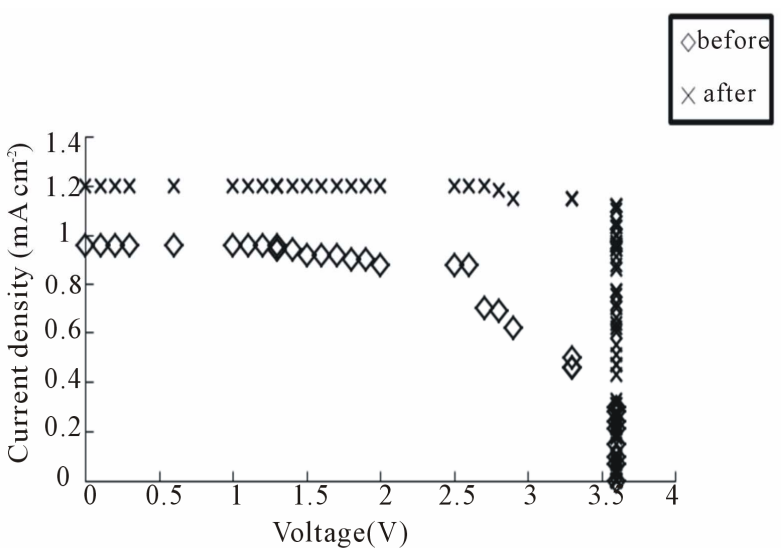

Figure 11. Photocurrent-voltage curves for PMMA/ponceau 2R LSC before and after coupled with photovoltaic cell.

polymer-dye mixed samples was obey a first-order kinetic equation and homo PMMA/ponceau 2R has lower degradation rate. The obtained results showed also that the values of optical gap energy and the tail width of the
Table 3. Photovoltaic parameters of photovoltaic cell before and after coupling with PMMA/ponceau 2R collector.

\begin{tabular}{ccccccc}
\hline Samples & $\begin{array}{c}J_{s c} \\
\left(\mathrm{~mA} \cdot \mathrm{cm}^{-2}\right)\end{array}$ & $\begin{array}{c}V_{o c} \\
(\mathrm{~V})\end{array}$ & $\begin{array}{c}J_{m} \\
\left(\mathrm{~mA} \cdot \mathrm{cm}^{-2}\right)\end{array}$ & $\begin{array}{c}V_{m} \\
(\mathrm{~V})\end{array}$ & $F F$ & $\eta \%$ \\
\hline Before & 0.98 & 2.4 & 0.80 & 2.30 & 0.7823 & 0.86 \\
After & 1.20 & 3.6 & 1.12 & 3.45 & 0.8940 & 1.80 \\
\hline
\end{tabular}

$J_{s c}$ : Short circuit current; $F F$ : Fill factor; $V_{o c}$ : Open circuit voltage; $\eta$ : Overall energy conversion yield; $J_{m}$ : Maximum current; $V_{m}$ : Maximum voltage.

localized states in the band gap vary with the percentage of the MMA/ST. The change in values of $E_{g}$ and $E_{u}$ after irradiation for homo PMMA is less than copolymer and homo PS LSCs. Fluorescent measurements reveal that ponceau $2 \mathrm{R}$ has the highest fluorescence intensity and the highest fluorescence quantum yield in homo PMMA compared with the other matrixes. Thus the obtained homo PMMA/ponceau 2R can be applied as luminescent solar collector. The photovoltaic cell $2 \%$ photoelectric conversion was obtained. 


\section{Acknowledgements}

The authors very gratefully thank the King Abdulaziz City for Science and Technology for cooperation and support (AT-18-91).

\section{REFERENCES}

[1] M. Buffa, S. Carturan, M. G. Debije, A. Quaranta and G. Maggion, "Dye-Doped Polysiloxane Rubbers for Luminescent Solar Concentrator Systems," Solar Energy Materials and Solar Cell, Vol. 103, 2012, pp. 114-118. doi:10.1016/j.solmat.2012.04.019

[2] A. Gnanamani, M. Bhaskar, R. Ganeshjeevan, R. Chandrasekar, G. Sekaran, S. Sadulla and G. Radhakrishnan, "Enzymatic and Chemical Catalysis of Xylidine Ponceau 2R and Evaluation of Products Released," Process Biochemistry, Vol. 40, No. 11, 2005, pp. 3497-3504. doi:10.1016/j.procbio.2005.03.053

[3] S. M. Reda, "Photostability of Ponceau 2R Doped Thin Film Sol-Gel Silica as Luminescent Solar Collector," Energy Research Journal, Vol. 1, No. 1, 2010, pp. 36-41.

[4] A. F. Mansour, "On Enhancing the Efficiency of Solar Cells and Extending Their Performance Life," Polymer Testing, Vol. 22, No. 5, 2003, pp. 491-495. doi:10.1016/S0142-9418(02)00055-7

[5] A. F. Mansour, "Photostability and Optical Parameters of Copolymerstyrene/MMA as a Matrix for the Dyes Used in Fluorescent," Polymer Testing, Vol. 23, No. 3, 2004, pp. 247-252. doi:10.1016/j.polymertesting.2003.09.010

[6] A. F. Mansour, H. M. A. Killa, S. Abd El-Wanees and M. Y. El-Sayed, "Laser Dyes Doped with Poly(ST-Co-MMA) as Fluorescent Solarcollectors and Their Field Performance," Polymer Testing, Vol. 24, No. 4, 2005, pp. 519525. doi:10.1016/j.polymertesting.2004.11.014

[7] H. M. Zidan and M. Abou-Elnader, "Structural and Optical Properties of Pure PMMA and Metal Chloride-Doped PMMA Films," Physica B, Vol. 355, No. 1, 2005, pp. 308317. doi:10.1016/j.physb.2004.11.023

[8] V. Thiagarajan, C. Selvaraju and P. Ramamurthy, "Excited State Behaviour of Acridinedione Dyes in PMMA Matrix: Inhomogeneous Broadening and Enhancement of Triplet," Journal of Photochemistry and Photobiology A: Chemistry, Vol. 157, No. 1, 2003, pp. 23-31. doi:10.1016/S1010-6030(03)00079-0

[9] S. Bistac and J. Schultz, "Study of Solution-Cast Films of PMMA by Dielectric Spectroscopy: Influence of the Nature of the Solvent on and Relaxations," Adhesion and Adhesives, Vol. 17, No. 2, 1997, pp. 197-201. doi:10.1016/S0143-7496(97)00001-8

[10] X. B. Cheng, M. Liang, Z. Sun, S. Xue, Q. P. Wu, Y. J. $\mathrm{Xu}$, "Synthesis of Triarylamines with Secondary ElectronDonating Groups for Dye-Sensitized Solar Cells," Solar Energy, Vol. 86, No. 2, 2012, pp. 764-777. doi:10.1016/j.solener.2011.12.005 